\title{
Glucagon-Like Peptide-1 Analogues and Anxiety and Abnormal Eating Behaviours in Type 2 Diabetes: A Case Report
}

Anne Marie Doherty ${ }^{1^{*}}$, Rosarie Atkinson ${ }^{2}$ and Mark Chamley ${ }^{3}$

${ }^{1}$ Consultant Liaison Psychiatrist,Diabetes Department, King's College Hospital, London, UK

${ }^{2}$ Diabetes Specialist Nurse, Lambeth Diabetes Intermediate Community Team, Crown Dale Medical Centre, UK

${ }^{3}$ General Practitioner Lead, Lambeth Diabetes Intermediate Community Team, Crown Dale Medical Centre, UK

*Corresponding author: Anne Marie Doherty, Diabetes Department, King's College Hospital, London, SE5 9RS, United Kingdom, Tel: +44 (0)203 299 1350 ; Fax: +44 (0)203 299 1350; E-mail: annedohertyemail@gmail.com

Rec date: May 05, 2014, Acc date: May 29, 2014, Pub date: June 04, 2014

Copyright: ( 2014 Doherty AM et al. This is an open-access article distributed under the terms of the Creative Commons Attribution License, which permits unrestricted use, distribution, and reproduction in any medium, provided the original author and source are credited.

\begin{abstract}
Psychological and psychiatric problems are common in diabetes. Glucagon-like peptide-1 (GLP-1) analogues are effective in the management of type 2 diabetes as second or third-line treatment, and are thought to have a central effect on appetite regulation. There is little evidence regarding the effect of GLP-1 analogues on anxiety.

This is a case report of a patient with type 2 diabetes, obesity, anxiety and disordered eating who was commenced on Liraglutide, a glucagon-like peptide-1 (GLP-1) analogue.

This patient reported, in addition to improved glycaemic control, a marked improvement in the anxiety which had been present all her life, and had driven her binge eating. This anxiety had persisted despite anxiolytic medications and cognitive behaviour therapy.

Any medication which could have a positive effect on anxiety and diabetes both would be valuable. Glucagon like peptide analogues may have a role in the management of co-morbid anxiety and type 2 diabetes. Further research is required into this area.
\end{abstract}

Keywords: Glucagon-like peptide-1; GLP-1 analogue; Diabetes; Anxiety; Psychiatry

\section{Abbreviations}

BMI: Body Mass Index; GLP-1: Glucagon-Like Peptide-1; HbA1c: GlycatedHaemoglobin; IBS: Irritable Bowel Syndrome; SSRI: Selective Serotonin Reuptake Inhibitor

\section{Background}

Glucagon-like peptide-1 (GLP-1) is an anorexigenic peptide which is produced centrally in the preproglucagon neurons of the nucleus tractussolitarius of the medulla oblongata, and peripherally in the pancreas and gastro-intestinal tract [1]. GLP-1 receptors are expressed widely throughout the central nervous system, but especially in the mesolimbic pathway which moderates reward [2].

GLP-1 analogues are effective in the management of type 2 diabetes and are indicated as third-line treatment where the body mass index (BMI) is greater than or equal to $35 \mathrm{~kg} / \mathrm{m}^{2}$ [3]. There is evidence for its use as a second-line agent where metformin monotherapy has failed [4]. GLP-1 analogues cause the release of insulin when blood glucose becomes elevated post-prandially, and reduce gastric emptying. People with diabetes have been observed to lose body weight on GLP-1 analogue treatment, and it has been hypothesised that this may be due to its central effect on the mesolimbic system [5].
One animal study demonstrated a reduction in alcohol intake in response to the administration of GLP-1 or an analogue, thus indicating that GLP-1 may have a role in modulating alcohol intake and reward [6]. Similar finding were reported in rats where the locomotor response precipitated by the psycho stimulant amphetamine was modulated by the administration of GLP-1 [7]. These findings have not yet been replicated in humans.

GLP-1 analogues have been shown to have potential benefit in the management of irritable bowel syndrome (IBS) in non-diabetic individuals, and although this is considered to be due to its peripheral rather than its central effect, the site of the altered activity has not been definitively identified. This is relevant given the association between anxiety and IBS, and effect of psychological stress on hormonal changes influencing gastric motility in IBS $[8,9]$.

There is little evidence available regarding the effect of GLP-1 on anxiety. Animal models reported increased anxiety when exposed to exenatide [10]. In initial clinical trials it was reported that there was no increase in anxiety levels in human subjects. The LEAD-3 study which examined the effect of liraglutide on patient-reported measures, reported non-significant improvements in anxiety $(\mathrm{p}=0.09)$ and depression $(\mathrm{p}=0.057)$ and significant improvements in global psychological well-being $(\mathrm{p}=0.002)$ and behavioural/emotional control $(\mathrm{p}<0.0001)$. It attributed these improvements to globally increased satisfaction with improved glycaemic control and weight reduction, rather than to a central effect of the GLP-1 analogue per se [11]. One small clinical study reported reduced symptoms of depression and anxiety in patients commenced on GLP-1 analogues $(n=71)$ in 
Page 2 of 3

comparison with those commenced on insulin [12]. The exact mechanism whereby GLP-1 mediates an effect on anxiety remains unclear, but it is likely to be associated with receptors in the mesolimbic system.

There is evidence of central action of exenatide in fMRI studies [13], and some early neuro-physiology studies have examined the role of GLP-1 in the biomechanisms behind eating disorders, finding a correlation between impaired post-prandial secretion of GLP-1 and active bingeing-vomiting behaviours in bulaemia nervosa [14].

\section{Case Presentation}

KR, a 61 year old woman of mixed ethnicity with a history of anxiety and depression, and a 5 year history of diabetes was referred to a diabetes psychiatrist for assessment, via our 3 Dimensions of Care for Diabetes project with $\mathrm{HbAlc}$ of $123 \mathrm{mmol} / \mathrm{mol}$ and BMI of $38.7 \mathrm{~kg} / \mathrm{m}^{2}$. She was concurrently prescribed maximum oral therapies, and had declined referral to the diabetes team as she did not wish to start insulin.

On assessment by the psychiatrist she presented with symptoms of anxiety, depression and binge- eating disorder (or eating disorder not otherwise specified: ED-NOS), characterised by binge-eating in response to anxiety, which had resulted in obesity. She had been partially treated for her mood in the past on citalopram $10 \mathrm{mg}$, which she had been taking for several years.

She reported lifelong poor eating habits, originating in her childhood. She reported a difficult childhood with many psychological traumas, and specific problems relating to food and weight. Notably she described her mother's unusual eating patterns as "binge or starve", and that these eating patterns were imposed on the family. From an early age she was described by both parents as unattractive and fat, even when her weight was within normal range. She had subsequently had 3 difficult marriages, and more recently had a number of significant social stressors in her life. These difficulties made it difficult for her to prioritise her diabetes self-management or to engage in life-style change.

Her dislike of insulin could be traced to her experiences as a young child, where her maternal grandfather, who lived with her family and had diabetes and depression, spent much of his time lamenting his diagnoses and his need to self-inject insulin, until his untimely death, likely from suicide.

In clinic, we increased citalopram to a therapeutic dose $(20 \mathrm{mg}$ daily). She engaged in cognitive behaviour therapy and progressed well, making significant lifestyle changes. Her mood improved and she reported feeling significantly more in control of her life, and of her diabetes. Her HbAlc improved to $74 \mathrm{mmol} / \mathrm{mol}$ in three months and she eventually agreed to attend the diabetes clinic. During this time, although being greatly improved, she still described an internal sense of agitation which she attempted to alleviate by eating, and continued to struggle to control this compulsive drive to eat.

After 18 weeks, she consented to assessment by the diabetes team and was commenced on a glucagon-like peptide-1 analogue (GLP-1), liraglutide. This commenced 20 weeks following the increase in Citalopram and 18 weeks following the commencement of CBT. Within 10 days of a therapeutic dose of $1.2 \mathrm{mg}$ she reported a subjective reduction in the lifelong internal anxiety she had previously described, resulting in a reduced drive to alleviate this by eating. She also suddenly stopped biting her nails, another life-long anxiety-driven habit. After 2 months her HbAlc dropped to $51 \mathrm{mmol} / \mathrm{mol}$ (Figure 1).

\begin{tabular}{|c|c|}
\hline 0 weeks & \begin{tabular}{|l|}
- Assessment, and increased Citalopram to $20 \mathrm{mg}$ \\
$\cdot \mathrm{HbA} 1 \mathrm{c}=123 \mathrm{mmol} / \mathrm{mol}$
\end{tabular} \\
\hline 2 weeks & - Commenced CBT \\
\hline 18 weeks & $\begin{array}{l}\text {-Agreed to assessment by diabetes team } \\
-\mathrm{HbA1 \textrm {C }}=74 \mathrm{mmol} / \mathrm{mol}\end{array}$ \\
\hline 20 weeks & -GLP-1 commenced \\
\hline 22 weeks & - Reported sudden improvement in anxiety \\
\hline 30 weeks & $\cdot \mathrm{HbA} 1 \mathrm{c}=51 \mathrm{mmol} / \mathrm{mol}$ \\
\hline
\end{tabular}

Figure 1: HbA1c levels

\section{Conclusions}

In addition to illustrating the importance of multi-disciplinary and psychological expertise as part of routine diabetes care, this case demonstrates that there may be a specific role for GLP-1 analogues in the management of patients whose diabetes is complicated by psychological pathology. GLP-1 analogues may prove particularly useful in the management of co-morbid anxiety or binge-eating disorder. Their potential in the management of mood disorders has been previously discussed [15].

There is uncertainty regarding the mechanism whereby this effect occurs. The LEAD-3 study attributed non-significant improvements in anxiety to globally increased satisfaction with improved glycaemic control and weight reduction, rather than to a central effect of the GLP-1 analogue per se [11]. Given the evidence from animal studies of GLP-1-induced reduction in alcohol intake and in the modulation of the locomotor response precipitated by amphetamine indicates that the reward centres (mesolimbic pathway) may have a role in this effect $[6,7]$. Further evidence of central action of exenatide in fMRI studies [13], supports this: although the exact mechanism whereby GLP-1 mediates an effect on anxiety remains unclear, it is likely to be associated with receptors in the mesolimbic system.

Unfortunately we did not conduct quantitative assessments of anxiety at the various time-points where treatments were changed, which is a limitation of this paper. However, anxiety is by definition a subjective experience, and clinical improvement is the measure most commonly used in clinical practice.

Is there a role for GLP- 1 analogues in the treatment of binge-eating disorder in patients with diabetes? Based on this case, there may be. However more research is needed into this promising finding.

\section{Consent}

Written informed consent was obtained from the patient for publication of this case report.

\section{Disclosure}

The authors report no proprietary or commercial interest in any product mentioned or concept discussed in this article. 
Citation: Doherty AM, Atkinson R, Chamley M (2014) Glucagon-Like Peptide-1 Analogues and Anxiety and Abnormal Eating Behaviours in Type 2 Diabetes: A Case Report. J Diabetes Metab 5: 381. doi:10.4172/2155-6156.1000381

Page 3 of 3

\section{References}

1. Baggio LL, Drucker DJ (2007) Biology of incretins: GLP-1 and GIP. Gastroenterology 132: 2131-2157.

2. Barrera JG1, D'Alessio DA, Drucker DJ, Woods SC, Seeley RJ (2009) Differences in the central anorectic effects of glucagon-like peptide-1 and exendin-4 in rats. Diabetes 58: 2820-2827.

3. National Institute for Clinical Excellence (2010) Liraglutide for the treatment of type 2 diabetes mellitus. 2010, NICE, London.

4. Inzucci SE, Bergenstal RM, Buse JB, Diamant M, Ferrannini E, et al (2012) Management of hyperglycaemia in type 2 diabetes: a patientcentered approach. Position statement of the American Diabetes Association (ADA) and the European Association for the Study of Diabetes (EASD). Diabetes Care 55: 1364-13759.

5. vanBloemendaal L, Ten Kulve JS, la Fleur SE, Ijzerman RG, Diamant M (2013) Effects of GLP-1 on appetite and body weight: focus on the central nervous system. J Endocrinol 221: T1-T16.

6. Shirazi RH, Dickson SL, Skibicka KP (2013) Gut peptide GLP-1 and its analogue, Exendin-4, decrease alcohol intake and reward. PLoS One 8: e61965.

7. Erreger K, Davis AR, Poe AM, Greig NH, Stanwood GD, et al. (2012) Exendin-4 decreases amphetamine-induced locomotor activity. PhysiolBehav 106: 574-578.

8. Han B (2013) Correlation between gastrointestinal hormones and anxiety-depressive states in irritable bowel syndrome. ExpTher Med 6: 715-720.
9. Hellström PM (2011) GLP-1 playing the role of a gut regulatory compound. ActaPhysiol (Oxf) 201: 151-156.

10. Möller C, Sommer W, Thorsell A, Rimondini R, Heilig M (2002) Anxiogenic-like action of centrally administered glucagon-like peptide-1 in a punished drinking test. Prog Neuropsychopharmacol Biol Psychiatry 26: 119-122.

11. Bode BW, Testa MA, Magwire M, Hale PM, Hammer M, et al. (2010) Patient-reported outcomes following treatment with the human GLP-1 analogue liraglutide or glimepiride in monotherapy: results from a randomized controlled trial in patients with type 2 diabetes. Diabetes Obes Metab 12: 604-612.

12. Grant P, Lipscomb D, Quin J (2011) Psychological and quality of life changes in patients using GLP-1 analogues. J Diabetes Complications 25: 244-246.

13. De Silva A, Salem V, Long CJ, Makwana A, Newbould RD, et al. (2011) The gut hormones PYY 3-36 and GLP-1 7-36 amide reduce food intake and modulate brain activity in appetite centers in humans. Cell Metab 14: 700-706.

14. Brambilla F, Monteleone P, Maj M (2009) Glucagon-like peptide-1 secretion in bulimia nervosa. Psychiatry Res 169: 82-85.

15. McIntyre RS, Powell AM, Kaidanovich-Beilin O, Soczynska JK, Alsuwaidan M, et al. (2013) The neuroprotective effects of GLP-1: possible treatments for cognitive deficits in individuals with mood disorders. Behav Brain Res 237: 164-171. 